\title{
Study of Anabaena ambigua on Growth Parameters of Coriandrum sativum after Seed and Foliar Spray Treatment
}

\author{
Jayant Pralhad Rathod ${ }^{1 *}$, Pallavi Rathod ${ }^{1}$, Darasing R. Rathod ${ }^{2}$ and Rajendra M. Gade ${ }^{1}$ \\ ${ }^{1}$ Vasantrao Naik College of Agricultural Biotechnology, Dr. Panjabrao Deshmukh Krishi \\ Vidyapeeth, Waghapur Road, Yavatmal-445001, Maharashtra, India \\ ${ }^{2}$ Dr. Panjabrao Deshmukh Krishi Vidyapeeth, P.O. Krishi Nagar, Akola-444104, \\ Maharashtra, India \\ *Corresponding author
}

\section{Keywords}

Anabaena, Coriandrum, Biostimulant, Foliar, Growth parameters

Article Info

Accepted: xx November 2018 Available Online: xx December 2018

\section{A B S T R A C T}

The present study aimed at studying the biostimulant effect of cyanobacterial cultures on the growth parameters of Coriandrum Sativum. Cyanobacteria helped in absorption of atmospheric carbon dioxide and reduced its concentration to the level which is suitable for evolution of higher organisms. It is one of the oldest microbes and has evolved in many beneficial ways. It is known to produce exopolysaccharides, phytohormones and also have inherent nitrogen, phosphate and potassium for healthy growth of other plants. In this study, intact cyanobacterial cells were used for seed treatment and as foliar application on Coriandrum sativum and its effects were compared to untreated plants with respect to different growth parameters. In case of seed treated (ST) plants the percent germination, number of branches, root length, Chlorophyll a, Chlorophyll b were found to be increased as compared to untreated (UT) plants. While in case of foliar spray treatment (FST), shoot length, number of branches, Chlorophyll a and Chlorophyll $\mathrm{b}$ content were found to be increased as compared to UT plants. Thus application of cyanobacterial culture on vegetables may result in increased production organically. The results showed positive effect of both seed treatment and foliar spray treatment on C. sativum plants.

\section{Introduction}

Coriandrum Sativum (Coriander) also called as Kothimbir, Dhaniya, Harapatta, etc is widely used vegetable to make different food recipes because of its taste, aroma and nutritional contents (Hammer and Heller, 1998). Along with that it has several health benefits as it is rich in Vitamin (Hwang et al., 2014). Coriander helps in skin related disorder, reducing cough, reducing blood pressure, reducing Diarrhea, reducing the Cholesterol levels in the bloods (Hwang et al., 2014).

Farmers grow Coriander throughout the year because of its high demand in the market and taste. They use different chemical fertilizers for its growth which is deteriorating the health of soil. An alternative to chemical fertilizers, cyanobactrial strain was used as biostimulant to study its effect on its growth, productivity 
and nutritional content of this vegetable (Swarnalakshmi et al., 2013).

GC-MS analysis of Anabaena exudates showed the presence of n-acetyl-Dglucosamine, gibberellins, linalool, niacinamide and dihydroxyphenyl glycol (Essa et al., 2015). Anabaena culture contains these bioactive compounds might be responsible for cell enlargement, cell division and root initiation, along with their role in the activation of the antioxidative defense enzymes of plants (Essa et al., 2015). Cyanobacteria have been reported to benefit plants by producing amino acids, polypeptides, growth promoting regulators, vitamins, antibacterial and antifungal substances that improve plant growth and productivity (Riahi, 2013). Ismail and AboHamad (2017) studied the effect of Anabaena culture on growth parameters and physiological aspects of Barley and Fenugreek.

Cyanobacterial treatments increased those plants germination percentage, length of shoot, fresh and dry weights. The photosynthetic pigments (Chlorophylls and carotenes), proteins, glutamic-oxaloacetic and glutamic-pyruvic transaminases activities were also increased. They had attributed the plant growth promotive effect to the bioactive materials like exopolysaccharides, phytohormones, nitrogen, phosphorus and potassium in the cyanobacterial biomass (Ismail and Abo-Hamad 2017).

On the similar lines the experiments were planned on $C$. Sativum and analysis with respect to germination rate, root length, shoot length, number of branches, chlorophyll pigment, proteins, soils organic carbon, Nitrogen, Potassium and Phosphate were carried out in two different sets of experiments (Seed treatment and Foliar spray treatment compared with untreated plants).

\section{Materials and Methods}

For the current experiment, Coriandrum Sativum seeds were brought from the local farmers market of Yavatmal and stored at room temperature.

\section{Cyanobacterial strain and media composition}

The Cyanobacterial culture (Anabaena ambigua) was ordered from National Collection of Industrial Microorganism Pune (NCIM) and maintained on Fog's medium at light intensity of $\sim 6000$ lux at Room temperature.

Composition of Fog's medium

\begin{tabular}{|c|c|}
\hline $\mathrm{MgSO}_{4} .7 \mathrm{H}_{2} \mathrm{O}$ & $0.2 \mathrm{~g}$ \\
\hline K2HPO4 & $0.2 \mathrm{~g}$ \\
\hline $\mathrm{CaCl}_{2} \cdot \mathrm{H}_{2} \mathrm{O}$ & $0.1 \mathrm{~g}$ \\
\hline *Micronutrient solution & $1 \mathrm{ml}$ \\
\hline *Fe-EDTA solution & $5.0 \mathrm{ml}$ \\
\hline Agar(Difco) & $10.0 \mathrm{~g}$ \\
\hline $\mathrm{pH}$ & 7.5 \\
\hline Distilled water & $1.0 \mathrm{~L}$ \\
\hline \multicolumn{2}{|l|}{ Micronutrients solution } \\
\hline $\mathrm{H}_{3} \mathrm{BO}_{3}$ & $286.0 \mathrm{mg}$ \\
\hline $\mathrm{MnCl}_{2} \cdot 4 \mathrm{H}_{2} \mathrm{O}$ & $181.0 \mathrm{mg}$ \\
\hline $\mathrm{ZnSO}_{4} .7 \mathrm{H}_{2} \mathrm{O}$ & $22.0 \mathrm{mg}$ \\
\hline $\mathrm{Na}_{2} \mathrm{MoO}_{4} \cdot 2 \mathrm{H}_{2} \mathrm{O}$ & $39.0 \mathrm{mg}$ \\
\hline $\mathrm{CuSO}_{4} .5 \mathrm{H}_{2} \mathrm{O}$ & $8.0 \mathrm{mg}$ \\
\hline Distilled water & $100.0 \mathrm{ml}$ \\
\hline
\end{tabular}

In hot distilled water (D/W), $745.0 \mathrm{mg}$ of $\mathrm{Na}_{2}$ EDTA was dissolve completely and then added $557.0 \mathrm{mg}$ of $\mathrm{FeSO}_{4} .7 \mathrm{H}_{2} \mathrm{O}$.

The solution was boiled for few minutes and made up the volume to $100 \mathrm{ml}$ by $\mathrm{D} / \mathrm{W}$. 
Study of effect of A. ambigua culture on different parameters of coriander germination and growth

\section{Determination of growth of $A$. ambigua}

Optical density of A. ambigua culture was measured at $750 \mathrm{~nm}$ using spectrophotometer and Fog's culture media as blank.

\section{Experimental design}

The treatment of Coriander (seed and plant treatment) were divided into 3 sets, as

Untreated seeds (UT) / Control 5 set

Seeds/plantlets without any A. ambigua culture treatment.

Foliar Spray treatment (FST) -5 set

A. ambigua culture of optical density 1 was sprayed on plantlets by foliar spray application using spray pump.

Seed treatment (ST) -5 set

A. ambigua culture of optical density 1 was used to coat the Coriander seeds.

The seeds were dipped in cyanobacterial culture for 30 mins and then air dried before sowing them into soil.

\section{Growth condition}

The plantlets/vegetables were grown at light intensity of $\sim 6000$ lux at Room temperature.

\section{Parameters determined}

The plantlets were studied for various parameters mentioned underneath after seed treatment and foliar spray treatment with $A$. ambigua culture.

\section{Study of seed rate germination}

The percent rate of germination was calculated on the basis of number of seeds sown and number of plantlets grown, multiplied by 100 .

\section{Study of shoot length of plantlets}

The length of shoots was measured in $\mathrm{cm}$ using plastic scale.

\section{Study of number of branching of plantlets}

The number of branches were visually observed and noted.

\section{Study of root length of plantlets}

Root length of plantlets was measured using plastic scale in $\mathrm{cm}$.

Analysis of N, P, K and organic carbon content of soil

N, P, K and organic content of soil before and after treatment of cyanobacterial stimulant was analyzed from Krishi vighan Kendra of Yavatmal using standard protocols.

\section{Study of Chlorophyll and Carotenoids content}

The leaves of all the plantlets from same set (FST, ST and UT) were taken together and Chlorophyll and carotenoids content of plantlets were determined by using Rathod $e t$ al., (2016) for all sets of plantlets.

\section{Study of protein content}

The complete plantlets from same set (FST, ST and UT) were taken together to calculate total protein content of plantlets for all set which was determined by using Biuret method. BSA (Himedia) was used as standard for making standard curve. 


\section{Results and Discussion}

Average germination rate of Coriander for each set of ST and UT was taken and the results were shown in Table 1.

Percent increase in germination rate of ST was found to be $28.57 \%$ more as compared to UT. The results indicated positive effect of Anabaena seed treatment on Coriander plantlet. Similar results were observed by Essa et al., (2015), where he had got 30\% increase in the seed germination rate of Sorghum by Anabaena oryzae exudates. Also Kumar and Kaur, (2014), observed 62.9\% increased in wheat germination by using another Anabaena species namely Anabaena variabilis filtrate. Thus seed treatment with A. ambigua culture can be used as germination rate increasing strategy for different vegetable and crops.

Effect of Anabaena on shoot length of coriander was studied and given in Table 2 .

Percent increase in shoot length of FST plants was found to be more than UT plants. Percent increase in FST was $6.28 \%$ as compared to UT plantlets. In case of ST plants, plant height was less than UT by $4.02 \%$, it means foliar application is essential for plant's further growth and seed treated plants could help in increasing percent germination. Shariatmadari et al., (2013) also observed $42 \%$ increase in plant height of Squash plant, $84 \%$ increase in Cucumber and 56\% increase in Tomato by using Anabaena culture. The positive effect of cyanobacterial culture on shoot length or plant height was evident from all these studies.

To study the effect of Anabaena on branching of coriander so as to increase the weight of this vegetable, experiment was carried and observations were documented as shown in Table 3.

The percent increase in branching of ST was more as compared to UT plants. The percent increase in ST was found to be $36.84 \%$ more than UT. For FST it was found to be $21.92 \%$ more than UT plant. T-test value of ST was found to be significant. It clearly indicated the role of cyanobacterial culture on increase in branching of coriander plantlet which was beneficial for plant growth.

The effect of Anabaena on root length was observed and mentioned below in Table 4 .

Table.1 Effect of Anabaena on germination rate of Coriander (number of seeds germinated)

\begin{tabular}{|c|c|c|}
\hline Set & ST & UT \\
\hline $1^{\text {st }}$ & 2 & 1 \\
\hline $2^{\text {nd }}$ & 2 & 1 \\
\hline $3^{\text {rd }}$ & 2 & 1 \\
\hline $4^{\text {th }}$ & 2 & 2 \\
\hline $5^{\text {th }}$ & 1 & 2 \\
\hline A VERAGE \pm SD & $1.8 \pm 0.4$ & $1.4 \pm 0.48$ \\
\hline
\end{tabular}


Table.2 Effect of Anabaena on shoot length of coriander $(\mathrm{cm})$

\begin{tabular}{|c|c|c|c|}
\hline SET & FST & ST & UT \\
\hline $1^{\text {st }}$ & 8.33 & 4.8 & 6 \\
\hline $2^{\text {nd }}$ & 6.61 & 5.95 & 7 \\
\hline $3^{\text {rd }}$ & 5.85 & 6 & 5.5 \\
\hline $4^{\text {th }}$ & 5.2 & 7.05 & 5.3 \\
\hline $5^{\text {th }}$ & 7 & 6 & 7.25 \\
\hline A VERAGE \pm SD & $6.6 \pm 1.066$ & $5.96 \pm 0.712$ & $6.21 \pm 0.785$ \\
\hline
\end{tabular}

Table.3 Effect of Anabaena on branching of coriander plantlet (number of branches)

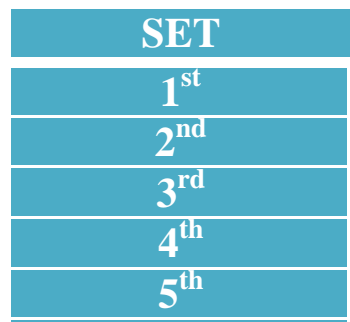

A VERAGE \pm SD

\begin{tabular}{|c|}
\hline FST \\
\hline 5 \\
\hline 2 \\
\hline 5.5 \\
\hline 6 \\
\hline 4.66 \\
\hline
\end{tabular}

$4.63 \pm 1.39$

\begin{tabular}{|c|c|}
\hline ST & UT \\
\hline 5 & 4 \\
\hline 6 & 2 \\
\hline 6 & 4 \\
\hline 5 & 5 \\
\hline 4 & 4 \\
\hline $5.2 \pm 0.74$ & $3.8 \pm 0.97$ \\
\hline
\end{tabular}

Table.4 Effect of Anabaena on root length of coriander $(\mathrm{cm})$

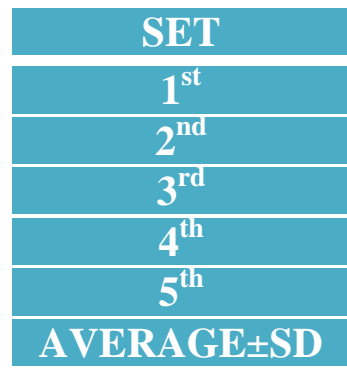

\begin{tabular}{|l|l|}
\hline & \\
\hline & \\
\hline & \\
\hline & \\
\hline & \\
\hline & an \\
\hline
\end{tabular}

FST

ST

2.6

UT

1.6

2.1

2

2

$-$

$1.92 \pm 0.192$

$2.95 \pm 0.606$

3.2

2.6

2.6

1.9

1.9

Table.5 Total Chl, Chl-a, Chl-b, Carotenoid Content of Coriander ( $\mu \mathrm{g} / \mathrm{gm})$ in different FST, ST and UT plantlets

\begin{tabular}{l}
\multicolumn{1}{c|}{ Parameters } \\
Total Chlorophyll \\
\hline Chlorophyll- a \\
\hline Chlorophyll- b \\
\hline Carotenoid
\end{tabular}

\begin{tabular}{|c|c|c|}
\hline FST & ST & UT \\
\hline 194.724 & 198.024 & 188.435 \\
\hline 67.6914 & 70.143 & 65.362 \\
\hline 127.102 & 127.951 & 123.140 \\
\hline 5.367 & 5.460 & 5.421 \\
\hline
\end{tabular}

Table.6 Total Protein Content of FST and ST as compared to UT plantlets (mg/gm)

\begin{tabular}{|c|c|c|c|} 
& FST & ST & UT \\
\hline Total Protein & 86.207 & 86.427 & 85.217 \\
\hline
\end{tabular}


Table.7 Effect of Anabaena on nutritional quality of soil

\begin{tabular}{|c|c|c|c|c|}
\hline & Organic carbon $(\%)$ & $\mathrm{N}(\mathrm{kg} / \mathrm{ha})$ & $\mathrm{P}(\mathrm{kg} / \mathrm{ha})$ & $\mathrm{K}(\mathrm{kg} / \mathrm{ha})$ \\
\hline FST & 0.44 & 196.68 & 30.1 & 255.0 \\
\hline ST & 0.40 & 178.8 & 28.2 & 270.0 \\
\hline UT & 0.35 & 156.45 & 29.1 & 280.0 \\
\hline
\end{tabular}

The percent increase in ST was more i.e. $22.91 \%$ as compared to UT plants. Contrary, percent decrease in FST was $19.79 \%$ less as compared to UT. Similarly Shariatmadari et al., (2013), found improvement in rooting of Squash, Cucumber and Tomato plants after useing Anabaena culture. This indicated the positive effect of seed coating of Anabaena culture on root length whereas negative effect after foliar spray on rooting. Although the root length was small but the shoot length was highest in folair application, which means foliar application increases the shoot length by acting on it and seed traetment stimulats the rooting. It also means plants were absorbing nutrients via leaf and there might not have much requirement of long root formation in foliar application. In future research both the effects together (seed treatment along with foliar application) will be studied.

The effect of foliar treatment on pigments such as total chlorophyll (Chl), Chlorophyll-a, chlorophyll-b and carotenoids were studied and mentioned below in Table 5 .

The total chlorophyll which determines the indirect overall photosynthetic capabilities was found to be slightly higher in FST and ST plantlets as compared to control UT plantlets. It was found to be $3.33 \%$ and $5 \%$ more in FST and ST with respect to UT plantlets. Chlorophyll-a was found to be $3.6 \%$ and $7.3 \%$ more in FST and ST compared to UT plantlets. Chlorophyll-b was also slightly got increased by $3.2 \%$ and 3.9\% in FST and ST compared to UT plantlets. Similar results with increase in Chlorophyll a and Chlorophyll b were observed by Ismail and Abo-Hamad, (2017) who studied the effect of Anabaena culture on growth parameters and physiological aspects of Barley and Fenugreek. There was no major difference found in carotenoids of FST and ST as compared to UT plantlets. Plants usually produce carotenoids in stressed conditions of high light and temperature (Rathod et al., 2016). The reason might be because the plantlets were grown in controlled conditions of light intensity. It will be interesting to see the effect under open atmospheric condition.

It was interesting to study the effect of Anabaena culture on coriander to determine the total increase in protein content of plantlets. It was found that there was not much difference found in FST and UT plants compared to controlled UT plantlets (Table 6). It was contrary to the results where increase in protein content was observed by Ismail and Abo-Hamad (2017) who studied the effect of Anabaena culture on growth parameters and physiological aspects of Barley and Fenugreek. It means that the proteins or amino acids present in Anabaena culture were not been able to directly utilize by the leaves in our case. Also, Ismail and Abo-Hamad (2017), utilized the cyanobacterial extract and not the complete cells and that can be one of the reasons of not increase in protein content in our case.

After seed and foliar treatment organic carbon, nitrogen, phosphorus and potassium content of soil were determined to study its effect. It was found that Anabaena culture positively increased the organic carbon 
content by $26 \%$ in case of FST treatment as compared to control Table 7. Also 14\% increase in ST was found as compared to control.

Thus Anabaena application is beneficial for increasing carbon content of soil. Similarly nitrogen content was found to be increased in FST and ST by $25 \%$ and $14 \%$ as compared to UT, which was positive sign. Although the plantlets did not directly take up the proteins or amino acids as shown earlier but it definitely increased the soil nutrients content which may be beneficial for subsequent vegetables or crops. The phosphate content of soil was slightly increased in case of FST treatment while it was slightly decreased in case of ST as compared to UT. The potassium content was found to be reduced in case of FST and ST treatment by $9.8 \%$ and $3.7 \%$, it might be because as other components (organic carbon and nitrogen) were available, potassium had got utilize in the process. Overall Anabaena positively impacted the soil quality and it could be one of the better options for organic farming.

The cyanobacterium is able to induce and increase seed germination in Coriander plants if applied directly to the seeds. The grown plants also show increase in branching, root induction and increase root length. The photosynthetic pigments like chlorophylls also get positively influenced by plants grown after seed treatment.

Foliar spray is very effective in increasing the shoot length, branching along with Chlorophyll a and Chlorophyll b in case of Coriander plants. Also the organic content and nitrogen content can be get increased by these treatments. Thus both the treatments showed positive effect on growth of plants and can be used as biostimulant for increased productivity and nutritional quality of vegetable plants.

\section{References}

Essa, A. M., Ibrahim, W. M., Mahmud, R. M., and ElKassim, N. A. 2015. Potential impact of cyanobacterial exudates on seed germination and antioxidant enzymes of crop plant seedlings. Int. J. Curr. Microbiol. App. Sci 4(6): 10101024.

Hammer K A, Heller J O. 1998. Promoting the conservation and use of underutilized and neglected crops. Schriften Genet Resour 8: 223227.

Hwang, E., Lee, D. G., Park, S. H., Oh, M. S., and Kim, S. Y. 2014. Coriander leaf extract exerts antioxidant activity and protects against UVB-induced photoaging of skin by regulation of procollagen type I and MMP-1 expression. Journal of medicinal food 17(9): 985-995.

Ismail, G., and Abo-Hamad, S. 2017. Effect of Different Anabaena variabilis (Kütz) Treatments on Some Growth Parameters and Physiological Aspects of Hordeum vulgare L. and Trigonella foenum-graecum L. Egyptian Journal of Botany 57(3): 507-516.

Kumar, A., and Kaur, R. 2014. Impact of cyanobacterial filtrate on seed germination behaviour of wheat. Int $\mathrm{J}$ Basic Appl Biol, 1(1): 11-15.

Rathod, J. P., Prakash, G., Vira, C., and Lali, A. M. 2016. Trehalose phosphate synthase overexpression in Parachlorella kessleri improves growth and photosynthetic performance under high light conditions. Preparative Biochemistry and Biotechnology, 46(8): 803-809.

Riahi, H., Shariatmadari, Z., Khanjir, M., and Azizi, A. 2013. Effect of Anabaena vaginicola inoculum on growth of pot plants. In International Symposium on 
Growing Media, Composting and Substrate Analysis 1013 (pp. 507-513).

Shariatmadari, Z., Riahi, H., Seyed Hashtroudi, M., Ghassempour, A., and Aghashariatmadary, Z. 2013. Plant growth promoting cyanobacteria and their distribution in terrestrial habitats of Iran. Soil science and plant nutrition, 59(4): 535-547.
Swarnalakshmi, K., Prasanna, R., Kumar, A., Pattnaik, S., Chakravarty, K., Shivay, Y. S., and Saxena, A. K. 2013. Evaluating the influence of novel cyanobacterial biofilmed biofertilizers on soil fertility and plant nutrition in wheat. European Journal of Soil Biology, 55: 107-116.

\section{How to cite this article:}

Jayant Pralhad Rathod, Pallavi Rathod, Darasing R. Rathod and Rajendra M. Gade. 2018. Study of Anabaena ambigua on Growth Parameters of Coriandrum sativum after Seed and Foliar Spray Treatment. Int.J.Curr.Microbiol.App.Sci. 7(12): 25-32. doi: https://doi.org/10.20546/ijcmas.2018.712.003 